\title{
OS SENTIDOS DO SENTIDO: UMA LEITURA FENOMENOLÓGICA
}

\author{
Los Sentidos del Sentido: Una Lectura Fenomenologica \\ The Meanings of Meaning: A Phenomenological Reading
}

Marta Helena de Freitas

Rita de CÁssia Araújo

Filipe Starling Loureiro Franca

Ondina Pena Pereira

Francisco Martins

\begin{abstract}
Resumo: Neste artigo, procedemos a uma leitura fenomenológica da noção de sentido e suas múltiplas significações. Partindo de uma primeira visada às definições apresentadas ao termo nos verbetes dos dicionários comuns, tal multiplicidade de significações é discutida à luz do conceito husserliano de "intencionalidade" e compreendida a partir da proposta merleau-pontyana de "reabilitação do sensível". Retomamos, então, o termo sentido desde suas acepções físicas e sensoriais até aquelas de cunho idealizado, relacional e teleológico, considerando-as como um conjunto expresso num único termo e que aponta para uma vida consciente baseada no campo da experiência corporal pré-predicativa desdobrando-se em experiência reflexiva, intersubjetiva e transcendental. Desta forma, o vocábulo sentido mostra-se como uma espécie de multiplicidade unificada e, por isso, considerado como que paradigmático: pura "mostração" do processo perceptivo, diante do qual se tem a contradição-continuidade da imanência (o dado imediatamente) e da transcendência (o que vai além do imediatamente dado). Discutimos as implicações desse entendimento para uma psicologia que se queira eficaz no seu processo de compreender a experiência humana fundamental em sua inserção no mundo da vida.
\end{abstract}

Palavras-chave: Sentido; Fenomenologia; Intencionalidade; Husserl; Merleau-Ponty.

Abstract: In this article we carried out a phenomenological reading of the notion of meaning and its multiple meanings. Starting from an initial target to the definitions provided in the dictionaries term, such a multiplicity of meanings is discussed in light of the Husserlian concept of "intentionality" and understood from the Merleau-Ponty propose about "rehabilitation of the sensible." Getting back the term direction from its physical and sensory meanings to those of idealized nature, relational and teleological, considering them as a whole expressed in a single term and points to a conscious life based in the field of body experience prepredicative unfolding in reflective experience, intersubjective and transcendental. Thus, the word order shows up as a kind of multiplicity unified and, therefore, considered that paradigm: pure "showing" the perceptual process, before which one has the contradiction-continuity of immanence (the immediately data) and transcendence (what goes beyond the immediately given). We discuss the implications of this understanding to a psychology that is effective in the process of understanding the fundamental human experience inserted in the living world.

Keywords: Meaning; Phenomenology; Intentionality; Husserl; Merleau-Ponty.

Resumen: En este texto, llevamos a cabo una lectura fenomenológica del concepto sentido y sus múltiples significados. Partiendo de un primero enfoque sobre las definiciones del término en los artículos de los diccionarios comunes, la multiplicidad de significados es examinada a la luz de la noción intencionalidad en Husserl y comprendida desde la propuesta de "rehabilitación de lo sensible" de Merleau-Ponty. Tomamos entonces el sentido del término desde sus significados sensoriales y físicos a los de naturaleza idealizada, teleológico y relacional, considerándolos como un conjunto que se expresa en un solo término y que apunta a una vida consciente fundada en el terreno de la experiencia pre-predicativa del cuerpo, con desdoblamientos en los terrenos reflexivo, intersubjetivo y trascendental. De esta manera, el sentido de la palabra se muestra como una especie de multiplicidad unificado y por lo tanto, lo consideramos paradigmático: es una demonstración del proceso perceptual, en lo cual tenemos la contradicción-continuidad de la inmanencia (lo inmediatamente dado) y la trascendencia (que va más allá de lo que se da de modo inmediato). Analizaremos las implicaciones de este entendimiento para una psicología que quisiera ser eficaz en su proceso de comprensión de la experiencia humana fundamental insertada en el mundo de la vida.

Palabras-clave: Dirección; Fenomenología; Intencionalidad; Husserl; Merleau-Ponty.

"De tudo o que vivo, enquanto o vivo, tenho diante de mim o sentido, sem o que não o viveria." Merleau-Ponty, A Fenomenologia da Percepção

(1945/1999, p. 41)
"Porque o único sentido oculto das cousas é elas não terem sentido oculto." Fernando Pessoa, Poemas Completos de Alberto Caeiro. 


\section{Introdução}

É no mínimo curioso como certas palavras nos soam como feixes de nomes, tal a multiplicidade de sentidos a que nos remetem. É este o caso do próprio vocábulo sentido. Qualquer bom dicionário o confirma. Mas, é no mundo da vida que o sentimos, cotidianamente. Falamos então dos órgãos do sentido, do sentido de um rio, do sentido desperto, do sentido tessitura, do sentido de uma palavra, frase ou texto, do olhar sentido, do amor sentido, da dor sentida, do coração sentido (ou ressentido), do sexto sentido, da fé sentida, do sentido da vida, do verbo sentir... E um novelo de sentidos se desfia.

Talvez sejam exatamente os sentidos intrínsecos à polissemia do termo "sentido" que o façam tão caro e especial à psicologia, sobretudo quando esta toma como seu objeto a experiência humana em sua plena vitalidade. Se tal vitalidade já foi muitas vezes evitada, negada e marginalizada na história desta mesma ciência, em nome de um certo tipo de rigor conceitual e metodológico que preferiu empregar vocábulos menos sujeitos a tantas ambiguidades, ela tem sido frequentemente resgatada ultimamente, e de várias maneiras. De fato, talvez o termo sentido nunca tenha estado tão em voga na psicologia, como em suas versões contemporâneas. Fala-se em "sentido do sintoma", "resgate de sentido", "busca de sentido", "construção de sentido", "núcleos de sentido", "representações do sentido", "sistema de sentidos", "vontade de sentido", "necessidade de sentido”, "encontro (ou reencontro) de sentido", "versão de sentido”, "fenomenologia do sentido", para falar dos mais frequentes.

Neste ensaio, porém, não pretendemos simplesmente apresentar mais uma abordagem acerca do termo sentido. Ao contrário, em vez de apresentar mais uma concepção concorrente a tantas outras, nosso intuito é o de discutir justamente essa multiplicidade natural do termo e suas respectivas vinculações à riqueza da experiência fundamental em causa. Evidentemente que seria tarefa hercúlea e, sobretudo, pretensiosa, propormos uma abordagem integradora de todas as demais já desenvolvidas em torno da concepção de sentido. Entretanto, podemos, ao menos, dirigir um olhar mais integrador sobre a própria experiência humana, tal como nos ensina, por exemplo, a fenomenologia de Husserl (1859-1938) e de MerleauPonty (1908-1961). Esse, então, o propósito do qual buscamos nos aproximar aqui: um exercício de apreensão fenomenológica dos sentidos do sentido e suas implicações para uma psicologia que se queira efetiva na abordagem ao mundo da vida.

\section{Do Dicionário à Noção Fenomenológica de Inten- cionalidade da Consciência}

Um dicionário comum da Língua Portuguesa que apresenta, de modo exaustivo, a variedade de significa- dos do termo sentido, pode relacionar até muito mais de vinte itens. O dicionário eletrônico Priberan da Língua Portuguesa (2010), por exemplo, apresenta 14 significados para o termo "sentido", no singular, número que se eleva para 18, quando o termo é empregado no plural "sentidos", e para 28 (!) quando se refere à conjugação do verbo "sentir". Considerando-se nosso intuito de realizar aqui uma espécie de "exegese” fenomenológica do termo, reproduziremos integralmente os três verbetes, conforme a seguir:

"Sentido: adj. 1. Ressentido; melindrado; magoado. 2. Sensível; susceptível; que se ofende facilmente. 3. Contristado; pesaroso; triste. 4. Lamentoso; plangente. s. m. 5. Faculdade que têm o homem e os animais de receber as impressões dos objectos exteriores. 6. Razão, bom senso. 7. Intento, mira, pensamento. 8. Atenção, cuidado. 9. Memória, cabeça. 10. Lado de uma coisa, direcção. 11. Significação. 12. Acepção. 13. Espírito, pensamento. 14. Modo, aspecto, ponto de vista, maneira de considerar ou de distinguir.

Sentidos: s. m. pl. 15. Conjunto das faculdades para a percepção dos objectos exteriores. 16. Conjunto das faculdades intelectuais. = RACIOCÍNIO 17. Voluptuosidade, prazer, sensualidade, concupiscência. interj. 18. Expressão usada para pedir concentração ou cuidado em relação a algo. = ATENÇÃO, CUIDADO com os cinco sentidos: com todo o cuidado, como é devido. sentido proibido: sentido contrário ao sentido normal de uma faixa de rodagem. = CONTRAMÃO. Sexto sentido: intuição.

Sentir - Conjugar (latim sentio, -ire, perceber pelos sentidos, perceber, pensar) v. tr. 1. Perceber por um dos sentidos; ter como sensação. 2. Perceber o que se passa em si; ter como sentimento. = EXPERIMENTAR. 3. Ser sensível a; ser impressionado por. 4. Estar convencido ou persuadido de. = ACHAR, CONSIDERAR, JULGAR, PENSAR. 5. Ter determinada opinião ou maneira de pensar sobre (algo ou alguém). = ACHAR, CONSIDERAR, JULGAR, REPUTAR. 6. Conhecer, notar, reconhecer. 7. Supor com certos fundamentos. $=$ CONJECTURAR =, PREVER. 8. Aperceber-se de, dar fé ou notícia de. = PERCEBER. 9. Ter a consciência de. = PERCEBER. 10. Compreender, certificar-se de. 11. Adivinhar, pressagiar, pressentir. 12. Conhecer por certos indícios. $=$ PRESSENTIR 13. Ouvir indistintamente. = ENTREOUVI. 14. Experimentar mudança ou alteração física ou moral por causa de. = RESSENTIR. 15. Sofrer as consequências de. 16. Sentir tristeza ou constrangimento em relação a; afligir-se por. = LAMENTAR. 17. Ressentir-se, melindrar-se ou ofender-se com (algo). 18. [Belas-artes] Ter o sentimento estético. 19. [Belas-artes] Saber traduzir por meio da arte. v. intr. 20. Ter a faculdade de sentir. 21. Ter sensibilidade; ter alma sensível. 22. Sofrer. v. pron. 23. Experimentar um sentimento ou uma sensação. 
24. Ter a consciência de algum fenómeno ou do que se passa no interior de si mesmo. = RECONHECER-SE. 25. Apreciar o seu estado físico ou moral. = CRER-SE, IMAGINAR-SE, JULGAR-SE, REPUTAR-SE. 26. Tomar algo como ofensa. = MELINDRAR-SE, OFENDER-SE, RESSENTIR-SE s. m. 27. Sentimento, sensibilidade. 28. Maneira de pensar ou de ver. = OPINIÃO, ENTENDER, PARECER”.

Essa variedade ainda não esgota todos os significados possíveis do termo sentido, o que pode ser verificado quando se compara com outro verbete correspondente ao mesmo termo em outro dicionário, como por exemplo o Dicionário On Line Michaelis - Moderno Dicionário da Língua Portuguesa (1998/2009), que convidamos o leitor a buscar, pois sua reprodução, como de tantos outros, tomaria muito espaço nos limites deste ensaio.

O que é interessante observar de saída é que, dentre as diferentes acepções do termo, existem aquelas que remetem às funções biológicas, como os órgãos dos sentidos, por exemplo, mas também muitas outras - a maioria, inclusive - que nos remetem às chamadas "funções psíquicas”, classicamente descritas pela psicologia em seus diferentes níveis. Assim, podemos identificar, dentre os vários significados relacionados no verbete, desde aqueles que remetem às chamadas "funções básicas", mais diretamente vinculadas ao corpo - como a sensação e a percepção, passando pelas relacionadas às chamadas "funções intermediárias" - humor, afeto e sensibilidade, culminando nas que se associam às chamadas "funções superiores" - memória, consciência, sentimento, linguagem, pensamento e juízo. Por outro lado, se a maioria dos significados elencados nos verbetes podem ser relacionados a estes diferentes níveis do psiquismo, os quais, no seu conjunto, podemos chamar de "subjetividade", notemos também que alguns deles remetem a algo que a ultrapassa, seja por fazer referência à física (sentido enquanto lado de uma coisa, ou enquanto rumo ou direção de uma linha, força ou movimento) ou à cultura (sentido enquanto voz de comando e respectiva posição da tropa no contexto militar).

Ora, se as definições dos dicionários comuns buscam relacionar justamente os diferentes significados dos termos conforme o seu emprego cotidiano, num dado contexto linguístico e cultural, podemos compreender essa multiplicidade de aspectos relacionados ao termo sentido como ilustrando justamente aquilo que ocorre com a nossa consciência no mundo da vida (Lebenswelt). Sendo assim, o termo sentido, no contexto das línguas latinas, parece-nos paradigmático por evidenciar aquilo que Husserl (1931/2001, p. 48), inspirado em Brentano (18381917), chamou de "intencionalidade" da consciência: "particularidade intrínseca e geral que a consciência tem de ser consciência de qualquer coisa, de trazer, na sua qualidade de cogito, o seu cogitatum em si próprio” (grifo nosso). Essa multiplicidade intrínseca ao termo sentido - que remete, simultaneamente, a concepções da física, da fisiologia, do psiquismo e da cultura - confirma a já tão denunciada falsa dicotomia estabelecida pelo pensamento moderno através das distinções entre cogito e cogitatum, entre mundo exterior e mundo interior, entre objetividade e subjetividade, entre natureza e sensibilidade.

Por outro lado, curiosamente, podemos verificar também que, em geral, os sentidos do termo sentido estão intrinsicamente relacionados à própria noção fenomenológica de intencionalidade. Senão, vejamos. Esta noção está presente no conhecimento desde o neoplatonismo árabe, passando por Santo Tomás e Ockhman, no mundo medieval, tendo sido recuperada modernamente por Brentano (1838-1917), e posteriormente retomada por Husserl (18591938), justamente por reconhecerem que só tem sentido falar de consciência enquanto consciência de algo, ou seja: a intencionalidade representa justamente o direcionamento da consciência em relação ao objeto, e vice-versa, o modo como tal objeto se apresenta à consciência. Como tal, a intencionalidade remonta a um contíguo mental em movimento ininterrupto em direção ao mundo. Por esse motivo, não faz sentido pensá-la como instância de conteúdos mentais fechados e estagnados. Deste modo, toda vez que se tenta descrever as propriedades restritas ao objeto a que ela se dirige, às suas próprias propriedades enquanto instância, estamos diante de um estado vivido com certa duração, portanto como uma espécie de registro temporal de determinado ponto onde o seu movimento, constantemente pendular, se situa naquela ocasião. Nesta sua contínua relação com o objeto, a consciência se realiza em intuições originárias, ou seja, ao modo como os fenômenos lhe aparecem. Assim, embora os fenômenos possuam uma multiplicidade de aspectos, eles aparecem à consciência como uma unidade idêntica a ela mesma, pois esta mesma consciência "tem a capacidade de ligar os aspectos ou estados vividos a outros por meio da síntese" (Silva, 2009, p. 45). Poderíamos dizer, então, que as diferentes noções de sentido são o testemunho desse movimento, evidenciando que, no mundo da vida, o fenômeno só existe em ato: suas propriedades não são restritas ao objeto em si mesmo, mas só existem em função daquele que o observa e, nessa visada, lhe atribui sentido.

Considerando-se o exposto, qualquer tentativa de encontrar uma possível "essência" (Wesenshau) da noção de sentido só pode ser alcançada a partir e de dentro do próprio mundo da vida (Lebenswelt). Conforme nos ensina Merleau-Ponty (1951/1973, p. 50), "é no curso de uma história sedimentada que se dá uma "gênese de sentido" (Sinngenesis). No intuito de aprofundarmos essa compreensão de uma espécie de fio ontológico que ata a diversidade na unidade - o sentido dos sentidos - procuraremos explorar em mais detalhes, no próximo subitem deste ensaio, as suas diversas nuanças, desde sua concepção enquanto corporeidade, passando pela noção de sensibilidade e mentalidade, até sua concepção propriamente teleológica. E, para tanto, caminharemos nas trilhas da 
reabilitação do sensível, proposta por Merleau-Ponty, em especial em sua Fenomenologia da Percepção (MerleauPonty, 1945/1999).

\section{Da Corporeidade à Transcendência}

Se considerarmos a noção de sentido segundo sua acepção meramente fisiológica, em referência aos órgãos receptores que nos trazem impressões sobre os objetos externos, estes são "considerados responsáveis pelos diferentes tipos de sensação que percebemos” (Japiassu \& Marcondes, 1996, p. 245). Desta perspectiva, o conceito de sentido relaciona-se, então, à função sensorial do corpo humano e é considerado porta aos estímulos do mundo externo: a sensação é considerada aqui a base para a percepção e para o conhecimento. Sentido, aqui, seria então o fenômeno psicológico causado pela estimulação do nosso organismo. Segundo esta mesma acepção de sentido, as sensações podem ser classificadas em externas ou sensoriais (as que provêm dos órgãos dos sentidos) e internas ou orgânicas (que provêm do interior do nosso organismo e são conhecidas como sinestesia). Esta última, então, remete à consciência corporal das próprias funções orgânicas, ou consciência de corporeidade.

A fenomenologia de Merleau-Ponty veio demonstrar, entretanto, que a delimitação entre sentido externo e sentido interno é grosseira. Como afirma o filósofo (Merleau-Ponty, 1945/1999), embora seja possível identificar funcionalmente cada órgão do sentido de modo isolado, é impossível reduzir o corpo em partes independentes e de modo desconectado. Deste modo, "os sentidos traduzem-se uns nos outros sem precisar de um intérprete”, como diz Sokolowski (2010, p. 137):

Os vários sentidos efetivam identidades através da sinestesia, do reconhecimento de um único objeto dado pelos vários sentidos distribuídos em toda parte de nosso corpo próprio. Essas variedades de partes sensíveis, noéticas e noemáticas, servem como uma multiplicidade através da qual objetos vêm a ser identificados de mais e mais perspectivas: a árvore é vista, ouvida (no vento), tocada, cheirada; caminhamos em volta e subimos nela; podamos seus ramos e rompemos pedaços de casca morta; e em tudo isso uma e a mesma árvore é registrada em sua identidade e suas muitas características.

Assim, em relação ao sentido enquanto sensação, observa-se que ninguém diz que "sente" quando usa os sentidos fisiológicos. Em vez disso, há uma apropriação das qualidades aos seres mais amplos e complexos do que a sensação isolada de sua qualidade como parte integrante. E então, ao invés de dizermos que sentimos o frio, vemos o verde e engolimos o doce, dizemos que a água está fria, a mata é verde e que a fruta está doce.
Da mesma forma, todos os seres humanos têm os órgãos dos sentidos similares, mas o modo como suas capacidades são usadas e desenvolvidas tornam-se únicas. Cada um de nós sentimos e percebemos o mundo de uma maneira peculiar, pois isso envolve a própria história, a própria cultura e as crenças que advêm da nossa experiência subjetiva e intersubjetiva.

Por outro lado, é através do registro dos atos dos cinco sentidos que podemos dizer que temos um corpo. Para Husserl (1935/2008, p. 42), "homens e bichos não são simples corpos", mas o corpo é por excelência o meio de acesso ao mundo e de toda a experiência vivencial possível. Ou, para falarmos nos termos de Merleau-Ponty (1945/1999), o corpo “dissolve-se” neste mundo: ele é reconhecido como fundamento último de todos os processos de vivência. E assim, quando, em fenomenologia, nos referimos a corpo, não queremos fazer referência apenas à matéria (Körper), mas ao corpo animado (Leib). Deste modo, não é preciso refletir sobre os limites do próprio corpo, a todo o momento, mas se tem consciência dele. O corpo sintetiza a ambiguidade (imanência/transcendência) do ser no mundo. Na visão de Merleau-Ponty (1945/1999, p. 207-208), a imanência e a transcendência são dois elementos estruturais de qualquer ato perceptivo: "eu não estou diante de meu corpo, estou em meu corpo, ou antes, sou meu corpo".

Ora, a concepção de uma corporeidade nos remete à noção de sentido também enquanto faculdade para a percepção dos objetos exteriores e interiores. No modelo da psicologia clássica, considera-se que a passagem do sentido-sensação para o sentido-percepção é realizada pela capacidade intelectual do sujeito do conhecimento que organiza e dá sentido às sensações. Mais uma vez, a fenomenologia leva à superação da dicotomia na concepção do mundo sensível: não se pode estabelecer diferenças entre sensação e percepção, pois nunca temos sensações em partes ou de modo pontual, sendo impossível identificarmos sensações separadas de sua qualidade que, só depois, a mente uniria e organizaria como percepção de um objeto único. Na verdade, nós sentimos e percebemos formas como totalidades estruturadas e dotadas de significação e sentido (Chauí, 2003).

Para a fenomenologia, então, a percepção constitui-se uma fusão de sujeito-mundo, uma vivência verdadeira de uma experiência simultaneamente imediata e anterior a uma reflexão, num hipotético e espontâneo acordo sujeito e mundo. A percepção é sempre a percepção de algo, e nesse ato tem-se não só o sujeito, mas também um objeto para ele. Assim, o sentido definido como capacidade perceptiva é uma função cerebral que confere significado a estímulos sensoriais a partir da experiência de vida ou da memória. E é, também, simultaneamente, atividade sensível, emotiva e cognitiva que organiza e interpreta as impressões sensoriais, de modo intrínseco à própria conexão cerebral de todas elas para formar a percepção, utilizando-se da sinestesia, associação espontânea entre 
sensações de natureza diferente, mas que se mostram intimamente ligadas, variando segundo o sujeito da percepção. Deste modo, para Merleau-Ponty (1945/1999, p. 68), "nenhuma análise da percepção poder ignorar a percepção como fenômeno original, sob pena de ignorar-se a si mesma enquanto análise”. Afinal, ela é a configuração e a organização de todos esses elementos que a mente integrou nas experiências passadas, ligando e unificando-as, escolhendo-as por meio dos fatores de significação da linguagem e da cultura de cada um.

Nas definições de dicionários da Língua Portuguesa, o termo sentido é também empregado para se referir ao "sentir em ato" (feeling), ou ainda ao sentimento (feeling of), como uma reação afetiva ao que já ocorreu e como significado substantivado experimentado em relação a diversos fenômenos na vida, objetos, pessoas ou situações intelectuais ou morais. Aqui o termo é geralmente empregado para referir-se ao sentimento que se viveu. Em psicologia, é também considerado um estado afetivo geral, frequentemente relacionado por oposição ao conhecimento (Durozol, 1996) e como resultante de percepções sensoriais ou representações mentais. Segundo outra acepção, também comum em psicologia, sentido-sentimento constitui-se numa espécie de emoção mais delicada e de maior duração, representando formas afetivas mais estáveis, e distinguindo-se da emoção propriamente dita por ser revestido de um número maior de elementos intelectuais (Sousa, 2006). Como veremos a seguir, de novo a fenomenologia vem mostrar ser artificial esta dicotomia.

Para Merleau-Ponty, os sentimentos constituem uma linguagem, pois as formas de expressão dos sentimentos não são naturalmente dadas. As manifestações dos sentimentos são variadas e mas passam necessariamente pelo corpo. O próprio corpo é também o próprio ponto de vista sobre o mundo, o mediador entre a consciência e o mundo (Merleau-Ponty, 1945/1999). Portanto, todo ato físico terá um sentido interior. Todo sentimento terá sua contrapartida física e vice-versa: o homem considerado concretamente não é apenas um psiquismo unido a um organismo, mas uma constante oscilação da existência que ora é corporal e ora se dirige aos atos pessoais. Enfim, o corpo próprio não pode ser observado como a um objeto, pois meu corpo existe comigo (Merleau-Ponty, 1945/1999). Sendo assim, o corpo próprio é, simultaneamente, o sujeito da sensação, da percepção, do sentimento e do pensamento.

E aqui, então, nos deparamos com outra acepção de sentido comum nos dicionários: o sentido enquanto espírito, juízo e pensamento. Para Merleau-Ponty (1945/1999, p. 241), sentido-pensamento não se dá de modo dissociado de sentido-percepção: "A visão é um pensamento sujeito a um certo campo e é isso que chamamos de um sentido" (Merleau-Ponty, 1945/1999, p. 292). Dito de outro modo, este pensamento está para esta visão e "no final das contas, o cérebro e o olho talvez tenham uma relação contratual na qual o cérebro concorda em acreditar no que os olhos veem, mas, por sua vez, o olho concorda em ver aquilo que o cérebro quer." (Gilbert, 2006, p. 154) Da mesma forma, o sentido, enquanto pensamento, não se realiza separado do sentido-sentimento: "o sujeito pensante está ele próprio numa espécie de ignorância de seus pensamentos enquanto não os formulou ainda para si, ou mesmo não os disse ou escreveu.” (Merleau-Ponty, 1945/1999, p. 241). E não se pode separar o sujeito pensante do sujeito "sentinte”. O sujeito "sentinte" está também numa espécie de ignorância ou inoperância de seus sentimentos, enquanto não os expressar. A expressão poderá ser pela fala e esta será uma fala primária quando falar o próprio sentimento. Deste modo, ao sentido de felicidade que alguém experimenta ao ouvir uma música, considera-se como uma sensação, mas ao estado agradável e de prazer que permanece nesta sensação é o que se torna sentimento. A sensação que obtemos ao ouvir a música é passiva, pois não passa por um processo ativo de apreensão. Já o sentimento depende da essência da música e da observação da pessoa. A percepção do sentimento é um processo ativo e empírico de compreensão objetiva. Nas palavras de Merleau-Ponty (1945/1999, p. 178): “Os sentidos, e em geral, o corpo próprio apresentam o mistério de um conjunto que sem abandonar sua ecceidade e sua particularidade, emite, para além de si mesmo, significações capazes de fornecer sua armação a toda uma série de pensamentos e de experiências."

Assim, para o filósofo, o corpo é forma de expressão, pleno de intencionalidade e poder de significação. Cada movimento, cada gesto produzido é também pleno de sentidos, e o sentido dos gestos não é apenas dado, mas sobretudo, compreendido: "O corpo próprio está no mundo assim como o coração no organismo; ele mantém o espetáculo visível continuamente em vida, anima-o e alimenta-o interiormente, forma com ele um sistema" (Merleau-Ponty, 1945/1999, p. 273). O caminho proposto é partir do corpo como mediador à via do sentido, que é também o caminho da pessoa, do afeto, do pensamento, da linguagem e da comunicação.

A linguagem e a comunicação remetem-nos à acepção de sentido enquanto significado (meaning), termo também polissêmico, conforme se constata nos dicionários e no mundo da vida. Assim, ele pode referir-se a uma categoria linguística ou a uma interpretação específica, neste caso como significação, com uma intenção ou um fim determinado. É empregado também para se referir à expressividade de uma palavra, sua aceitação, sua intenção, sua significação, seu conteúdo semântico ou lexical. Refere-se, ainda, tanto ao objetivo subjacente ou destinado pela ação, pela fala ou outro modo de expressão, enfim, ao conteúdo válido, como também à interpretação interna, simbólica ou real, o valor ou a mensagem do significado de algo, como por exemplo, de um sonho. Por último, o significado pode ser ainda a definição, a explicação, 
a elucidação, a denotação discutindo sobre o significado exato da palavra, sua finalidade, seu objetivo final, a ideia, o projeto, o objeto, a intenção (Collins Thesaurus, 2003/2008). No campo específico da lexicologia e da linguística, entretanto, entende-se por sentido, enquanto significado, "cada um dos significados de uma palavra ou locução; acepção” (Dicionário Houaiss). Aqui falamos do sentido como parte de um signo linguístico, como um significado bem definido, denotativo, ao modo de um conceito, já definido previamente, dicionarizado.

Se as definições anteriores parecem remeter a uma desvinculação entre sentido enquanto sensorialidade/percepção e sentido linguístico, dando a impressão de que a linguagem nos distancia do corpo próprio, ressalte-se que a fenomenologia compreende-a como sendo ainda uma extensão dele. Para Husserl (1901/2000), a intencionalidade linguística categorial simplesmente humaniza a percepção, a recordação, a imaginação e as eleva a um nível mais racional, no qual o objeto é desdobrado diante de nós. Como tal, ela está relacionada ao chamado ato perceptivo categorial, ou ideal, um nível terciário do processo contínuo de percepção, que se nos revela como uma fusão de atos parciais num único ato. Como esclarecem Castro, Castro e Castro (2009, p. 96)

(...) no ato perceptivo categorial desdobramos o objeto diante de nós, destacamos as partes, estabelecemos relações entre estas partes destacadas, sejam relações de uma com a outra, sejam relações das partes com o todo, e por meio dessa percepção, dessa nova maneira de apreensão, os membros ligados e relacionados ganham o caráter de "partes" ou, respectivamente, de "todos".

Deste modo, a intencionalidade categorial é um tipo de identificação predicativa que vem suplementar e completar a que foi alcançada na experiência pré-predicativa. Ela nos eleva a um nível humano de construção da verdade que envolve a linguagem e o raciocínio. O seu contexto é, portanto, tão amplo e extenso como a gramática da linguagem humana. As categorias servem como princípio para a classificação onde os assuntos são integrados numa estrutura que constitui o universo de conhecimento. Os objetos categoriais são modos nos quais as coisas se apresentam. Aqui se evidencia a linguagem como um instrumento usado para a concepção do mundo, mas sua função de projetar esse mundo não se exaure no que pode ser alcançado a partir de um exame dos significados de palavras lexicais. De fato, o processo de significação extrapola o significado denotativo das palavras, incluindo a intencionalidade de quem está atribuindo significação. Podemos pensar aqui em termos do significado que uma experiência tem para uma determinada pessoa. Por ser intencional, a consciência humana sempre "faz o mundo aparecer como significação” (Zilles, 2002, p. 30). Como explica Merleau-Ponty (1945/1999, p. 576), “o sentido de uma frase é seu propósito ou sua intenção, o que supõe ainda um ponto de partida e um ponto de chegada, uma visada, um ponto de vista.” Para o filósofo, a fala surge como gesto do corpo que estabelece uma relação de sentido com o mundo, e "procurando descrever o fenômeno da fala e o ato expresso de significação poderemos ultrapassar definitivamente a dicotomia clássica entre sujeito e objeto" (Merleau-Ponty, 1945/1999, p. 237).

Nessa compreensão de corporeidade, então, vê-se que a noção de sentido se desloca para além da própria subjetividade, para incluir também a noção de espacialidade e temporalidade. E, por consequência, da intersubjetividade. Ser corpo, então, é estar ligado ao mundo; e o corpo não está no espaço primeiramente: "ele é no espaço" (Merleau-Ponty, 1945/1999, p. 205). Sendo assim, a percepção, em seus diferentes níveis, nos leva ao movimento em direção intencional ao mundo segundo as normas vitais do organismo, manifestando a atitude de se orientar em direção ao mundo. Pelo movimento nos comunicamos e nos relacionamos com tudo o que está ao nosso redor. Desde a mais tenra infância, é por meio da atividade motora que a criança se desenvolve e por adaptações contínuas vai adquirindo informações mais complexas, diversificadas e progressivamente mais elaboradas. A capacidade de nos movimentar permite respostas apropriadas ao ambiente, o que implica que a nossa orientação de atenção se concentra mais nas ações que fazemos do que nos movimentos propriamente ditos.

O exposto acima nos remete a outro conjunto de significados mormente dado ao termo sentido, qual seja, o de direção. Mas, a palavra direção também é polissêmica. Assim, numa primeira visada, ela pode se referir ao movimento físico - para frente, para trás, para o lado, para cima, para baixo, o qual se relaciona às direções básicas de espaço: norte, sul, leste e oeste. O sentido como direção é uma linha que conduz a um lugar ou ponto. É o itinerário, a rota, o caminho - uma linha estabelecida de viagens ou acesso: a direção ou o caminho, a relação espacial, ao longo da qual algo se move ou ao longo do qual se situa a tendência, as linhas gerais de orientação.

Por outro lado, no seu sentido ideativo, direção pode ser também um curso geral, no tempo, ao longo do qual algo tem uma tendência a desenvolver. Refere-se, portanto, a uma inclinação, uma tendência, uma disposição, uma atitude da mente. Este sentido é também o que mostra se a pessoa tem um plano de vida traçado, se ela está pensando no seu futuro e o construindo no presente. Simultaneamente, direção é algo que fornece direcionamento ou conselho a respeito de uma decisão ou curso de ação de aconselhamento, orientação, conselhos, mapas de estradas, um plano detalhado ou uma explicação para orientá-lo no estabelecimento de normas ou determinar um curso de ação (Collins Thesaurus, 2003/2008). 
Todos esses sentidos do termo "direção" possibilitam o direcionamento de um ato, tal como na noção de intencionalidade: "A intencionalidade da consciência é tal que alcança o mundo exterior todo o tempo, até quando tem por alvo coisas que não estão diante dela" (Sokolowski, 2010, p. 107). Assim, a intencionalidade do ato perceptivo, em seus diversos níveis, do orgânico ao ideativo, expressa-se através do corpo fenomenal e configura-se no meio existencial. É dessa forma que Merleau-Ponty (1945/1999) argumenta que espacialidade e esquema corporal convergem para o princípio ontológico do ser-no-mundo. E mais, o corpo como ser físico está presente, mas sem desconsiderar sua capacidade de transcendência. O corpo fenomenal é compreendido como o lugar existencial do ser-no-mundo; seu ethos. Na fenomenologia, corporalidade é a relação indissolúvel do corpo com o tempo, com o espaço e com o outro: a corporalidade não é apenas sinônima de um "eu”, é também sinônimo de maneiras de viver o tempo e o espaço.

O corpo é uma potência que nasce em conjunto com um meio e se sincroniza com ele. Por isto também o tempo só existe como passado, presente e futuro na medida em que se relaciona com o ser. Para Merleau-Ponty, portanto, o tempo não é apenas uma linha, mas antes, uma rede de intencionalidades. No âmbito desta rede, a consciência se volta para o mundo num modo de relação que não envolve uma compreensão racional a priori, mas um movimento próprio de si mesma em direção ao mundo, desde uma perspectiva pré-reflexiva. E é desta maneira que se pode compreender a noção de sentido também como intuição (Anschaunng), considerada em fenomenologia fonte de autoridade para o conhecimento (Martins \& Bicudo, 1989). De fato, a fenomenologia de Husserl busca “uma intuição originária”, nos moldes em que a descreve Dartigues (1973, p. 21): "se é verdade que os fenômenos se dão a nós por intermédio dos sentidos, eles se dão sempre como dotados de um sentido ou de uma "essência”. Eis por que, para além dos dados dos sentidos, a intuição será uma intuição da essência ou do sentido."

Deste modo, infere-se que a intuição da essência se distingue da percepção do fato. Ela é a própria visão do sentido ideal que se atribui ao fato materialmente dado e, ao mesmo tempo, o que se permite identificá-lo. MerleauPonty (1945/1999, p. 18) afirma que "porque estamos no mundo, estamos condenados ao sentido" e, assim, leva-nos a compreender o sentido também em termos de empatia, que se realiza na experiência intersubjetiva:

O mundo fenomenológico é não o ser puro, mas o sentido que transparece na intersecção de minhas experiências, e na intersecção de minhas experiências com aquelas do outro, pela engrenagem de umas nas outras; ele é, portanto inseparável da subjetividade e da intersubjetividade que formam sua unidade pela retomada de minhas experiências passadas em minhas experiências presentes, da experiência do outro na minha.

Podemos então compreender que as significações do termo sentido - variando desde suas acepções físicas e sensoriais até aquelas de cunho idealizado e relacional apontam para uma vida consciente baseada no campo da experiência corporal pré-predicativa e que se desdobra em experiência reflexiva e intersubjetiva. Deste modo, em toda percepção, tem-se também a contradição entre a imanência e a transcendência, que, na visão de Merleau-Ponty (1945/1999), são dois elementos estruturais de qualquer ato perceptivo, de modo que, sempre, objeto percebido é também conhecido ao sujeito que o percebe (imanência).

Por outro lado, toda percepção de algo tem uma não-percepção de alguma coisa que está para além do dado imediato, e que a transcende. Em outras palavras, toda vez que se tem consciência de algo, abre-se a possibilidade de não conhecer outros aspectos relacionados ao objeto percebido. Deste modo, quando estudamos um fenômeno temos apenas uma percepção parcial porque a experiência acompanha uma mistura de presença e ausência. "A percepção, então, envolve camadas de sínteses, camadas de múltiplas presentações, que são de dois tipos, atual e potencial" (Sokolowski, 2010, p. 28). E a identidade de um objeto transcende suas múltiplas manifestações porque vai além delas.

Assim, o sentido como transcendência, na fenomenologia, é aquilo que ultrapassa a própria atividade e alcance da consciência. As noções de noese e noema podem nos auxiliar aqui. Enquanto noese é termo empregado para se referir à própria atividade da consciência (sujeito intencionado), noema é usado em referência ao objeto (intuído) constituído por essa atividade, entendendo que há um mesmo campo de análise no qual a consciência aparece como se projetando para fora de si em direção a seu objeto e o objeto como fazendo referência aos atos da consciência (Dartigues, 1973). A noese e o noema ocorrem simultaneamente, em contínuo movimento, porque não há objeto em si, verdade em si, mas sempre em perspectivas e com sentido na esfera de compreensão do sujeito. A transcendência seria, então, o contínuo "pôr a descoberto" os diversos níveis que constituem o mundo da vida na busca de sentido.

Pode-se dizer, enfim, que a fenomenologia é um método de transcendência em seu contínuo e progressivo desvelamento do ser, do mundo e do ser-no-mundo. É um constante conhecer-se e este conhecimento passa pelo corpo, pois este não pode ser entendido como um simples organismo. Ele é também cultura, transcendendo o aspecto físico e, nas palavras de Merleau-Ponty (1945/1999, p. 257), “o uso que um homem fará de seu corpo é transcendente com respeito a este corpo como ser simples- 
mente biológico". Então se o corpo não é somente biológico, os comportamentos derivados dele também não o podem ser. Para ele o corpo sintetiza a ambiguidade (imanência/transcendência) do ser no mundo. Ele não é, diretamente, a única forma de expressão, pois é também um ser de linguagem, como expressão que modifica e transcende o fenômeno dado na percepção, ou seja, transcende a si mesma, pois seu movimento vai sempre no sentido de ir além das relações entre um mundo e outro.

A atitude fenomenológica e a redução fenomenológica são frequentemente denominadas transcendentais, tal como Husserl define o transcendental e Sokolowski a descreve (2010, p. 67):

A palavra significa ir além, baseada na sua raiz latina, transcendere, elevar-se sobre ou ir além, de trans e scando. A consciência, mesmo na atitude natural, é transcendental porque ela vai além de si mesma, até as identidades e coisas que lhe são dadas. $O$ ego pode ser chamado transcendental à medida que é envolvido, em cognição, no alcance das coisas. $\mathrm{O}$ ego transcendental é o ego ou o si mesmo como o agente da verdade. A redução transcendental é o giro em direção ao ego como o agente da verdade, e a atitude transcendental é a instância que assumimos quando exercermos esse ego e suas intencionalidades temáticas.

Vê-se, assim, que a transcendência está também relacionada ao sujeito. Para Bicudo (1999, p. 20), a transcendência, na fenomenologia, é "uma percepção retrospectiva do vivido, de modo que haja evidência dos fatos geradores do noema." Já Zilles (2001, p. 515) diz que "a subjetividade realiza-se na medida em que se transcende a si mesma por opção da liberdade." Este sujeito não é apenas psicológico, um ser que vive no mundo, mas um ser transcendente, aquele que vê o mundo como um conjunto de unidades de sentidos. Poderíamos dizer, então, que a transcendência é o sentido do sentido.

E é este mesmo sujeito que, em vendo - e vivendo - o mundo como um conjunto de unidades de sentido, formula, a partir de sua experiência no mundo, os múltiplos significados de um mesmo termo, os quais identificamos, sob a forma de verbete, na composição dos dicionários comuns. Podemos compreender, então, suas múltiplas significações como um conjunto de modalidades expressivas que se configuram, no mundo da vida, da imanência à transcendência, como que condensadas num único e mesmo termo: sentido.

\section{Das Modalidades Expressivas ao Mundo da Vida}

No mundo da vida, água não é apenas H2O. Ela é muito mais: é agua que mata a sede, é agua refrescante, é água solvente, é água da maré baixa ou alta, é água que apaga o fogo, é água que afoga, é água que rega a planta, é água purificadora, é água benta... Nenhum destes modos de ser água é menos verdadeiro que outro, embora se saiba que, na ausência da água que mata a sede, a pessoa morre. Daí a proposta husserliana de retorno às coisas mesmas, tal como elas aparecem no mundo da vida, para as pessoas de carne e osso. O mundo da vida apresenta essa riqueza de possibilidades e a fenomenologia busca estar alerta para captá-la em todas as suas facetas, e mais ainda: entende que a ciência só tem valor se ela estiver reconhecidamente comprometida com o mundo da vida. Este, sim, é o que lhe oferece a fundamentação axiológica; é dele, por ele e para ele que a ciência foi desenvolvida. Nas palavras de Merleau-Ponty (1945/1999, p. 3): “Todo o universo da ciência é construído sobre o mundo vivido, e se queremos pensar a própria ciência com rigor, apreciar exatamente seu sentido e seu alcance, precisamos primeiramente despertar essa experiência do mundo da qual ela é expressão segunda."

Desta perspectiva, então, qualquer formulação teórico-conceitual acerca de um objeto ou termo deve voltar-se inicialmente para os homens enquanto pessoas, para suas vidas e realizações existenciais. E como o esclarecera Husserl (1935/2008, p. 12), vida aqui não é tomada apenas no seu aspecto fisiológico, mas sim "vida ativa em vista de fins, realizadora de formações espirituais - no sentido mais lato, vida criadora de cultura na unidade de uma historicidade". Tal perspectiva implica em superar, pois, a dicotomia entre naturante e naturado, entre verdade objetiva e verdade subjetiva, entre o ser real das coisas e o seu parecer.

Ora, através do olhar fenomenológico, parece-nos que o termo sentido e sua multiplicidade de significações é uma ilustração de que a realidade não é única, estável ou universal, como o quer o princípio da não-contradição. Ao contrário, a realidade do mundo da vida é múltipla, variante e relativa, dependendo do olhar que lancemos sobre ela. E isso se dá não por uma falha conceitual ou metodológica, mas pela própria natureza do mundo da vida, que inclui tanto o ser como o parecer ser de qualquer coisa em que nele se apresente. Ou seja, a realidade no mundo da vida se dá não apenas a partir do que dela se mostra, mas também do que dela própria se transcende.

Esse modo de compreensão poderia ser apontado como metafísico, no sentido mais tradicional do termo. Mas, tal como o poeta homônimo de Fernando Pessoa, Alberto Caeiro, nos mostra que há metafísica bastante em não pensar em nada, a fenomenologia criada por Husserl vem mostrar que justamente a perspectiva positivista, que exige objetividade em lugar da expressividade, é que se caracterizaria como verdadeira metafísica. Afinal, ela entende que podemos superar a suposta ilusão dos sentidos a partir de determinados procedimentos metodológicos. Ora, ao fazer isso, ela se funda sobre um paradoxo: seria um determinado olhar, metodologicamente controlado, que nos levaria à verdade das coisas 
mesmas. Ou seja, sem se dar conta, a perspectiva positivista parte do princípio de que a objetividade não estaria no objeto em si, mas no olhar que ela mesma lança para o objeto; a objetividade estaria no procedimento e não na realidade; seria o olhar do cientista que atribuiria a objetividade à mesma. Ao qualificar o sentido, nas suas mais variadas expressões, a fenomenologia assume que a essência estaria na própria aparência das coisas, compreendendo que faz parte das coisas parecerem diferentes sob diferentes olhares. Ou seja, é da natureza do real mostrar-se e ocultar-se continuamente: as coisas se mostram sob um determinado olhar, mas elas também se escondem a esse mesmo olhar.

Do mesmo modo, se cada significado do termo sentido parece esconder o outro, ele também o mostra, não apenas pela sonoridade ou grafia de uma mesma palavra (sentido), mas pela dimensão de corporeidade e transcendência que se estendem desde sua concepção enquanto sensorialidade, passando pelos campos da sensibilidadeafeto e sentimento, da intersubjetividade - empatia e bom senso, da racionalidade - pensamento, conceito e juízo, mas realizando-se sempre no campo da espacialidade e da temporalidade - direção, destino - e culminando no campo da teleologia - propósito, finalidade.

\section{O Sentido dos Sentidos: entre o Buquê e o Jardim}

Para compreendermos a noção de sentido em uma perspectiva fenomenológica, podemos fazer uma analogia com o buquê de flores, tal como na semiologia de Roland Barthes (1966/2008). Sabemos que o buquêe composto por várias flores individuais, mas o buquê é mais que isso. Podemos dizer, acompanhando a Psicologia da Gestalt, que o todo é maior que a soma de suas partes. O mesmo vale para a questão do sentido. O sentido total da experiência engloba todas as modalidades de sentido apontadas no verbete de um dicionário, mas de modo integrado e interconectado. Assim, o que o corpo sente não é separado do significado e da sensação, isto é, a experiência corporal só pode ser entendida como uma realidade subjetiva onde o corpo, a percepção dele e os significados a que remetem se unem numa experiência única que vai além dos limites do corpo em si.

Se a ciência objetivista teve como consequência um empobrecimento da rica realidade do mundo da vida, a fenomenologia, ao resgatar a noção de sentido, vem propor a compreensão da realidade humana na sua proposta de retorno às coisas mesmas, de forma complexa, dinâmica, com múltiplas possibilidades de significação. Diríamos que o termo sentido é paradigmático em mostrar suas várias nuanças e, ao mesmo tempo, em superar a fragmentação da realidade. De alguma forma, a própria linguagem humana, através da polissemia do vocábulo sentido, conseguiu apreender a polivalência e multiplicidade do mundo perceptivo que não é o mundo meramente men- surável. A palavra sentido se mostra como um símbolo que contém múltiplos elementos, os quais, por sua vez, remetem a tantos outros elementos simbólicos, ilustrando o modo como Amatuzzi (1996, p. 20), ao fundamentar teoricamente o uso da versão de sentido, define símbolo: aquilo "que em si mesmo "reúne", põe junto uma série de coisas que antes estavam separadas, e o faz intencionalmente”. Há, implícita nesta multiplicidade unificada por meio de um mesmo símbolo, uma qualificação do movimento perceptivo-intuitivo, nos moldes em que o descreve Merleau-Ponty (1945/1999, p. 63):

(...) perceber no sentido pleno da palavra, que se opõe a imaginar, não é julgar, é aprender com sentido imanente ao sensível antes de qualquer juízo. O fenômeno da percepção verdadeira oferece, portanto, uma significação inerente aos signos, e do qual o juízo é apenas a expressão facultativa.

Pensemos no beijo por exemplo. O beijo envolve o sentido do tato, do paladar, do olfato, mas também envolve sentimento e um significado, que pode ser de paixão ou de indiferença. Envolve também uma noção de direção, podendo apontar para um desfecho da relação (um beijo frio, por exemplo) ou para um aprofundamento da mesma (um beijo apaixonado). E pode, ainda, conter elementos da ordem do ideal - romântico, sagrado ou religioso - quando se realiza também na metáfora do beijar o sapo, no ato de beijar a mão dos avós, ou no ritual de beijar o santo. Esses sentidos não são vividos pelas pessoas de maneira isolada, mas apreendidos como um todo. Portanto, um conceito que se quer fiel e completo ao sentido deste verbo - beijar - há que se referir a todas essas significações de modo intrinsecamente articulado.

Ao tentarmos descrever o buquê de sentidos, podemos falar dos diferentes aspectos separadamente, mas apenas para fins didáticos, como fazem os dicionários em cada item dos seus verbetes. Mas no mundo da vida eles são experimentados sempre como um todo integrado. Não existe sensação pura quando se trata de experiência humana. O sentido enquanto percepção fisiológica não existe separado do todo. Toda sensação é já imediatamente interpretação, significação. Um calafrio não é só uma experiência fisiológica - contração involuntária de músculos somáticos - mas pode ser significado como medo ou quem sabe como a passagem de um espírito por perto, como assim o interpretam alguns. Esta última forma de interpretar o calafrio não é menos verdade para a fenomenologia do que aquela primeira, pois ela também emerge na interação dos humanos com as coisas. O mundo, na perspectiva fenomenológica, é uma trama de significação. O mundo é também o conjunto de significados que atribuímos a ele. Nós somos os agentes criadores da realidade e toda realidade só existe em função de uma consciência que a apreende como tal. Qualquer ponto de vista é apenas a vista de um ponto. Qualificar 
o sentido dos sentidos, portanto, marca uma diferença epistemológica, assim explicitada por Merleau-Ponty (1945/1999, p. 13-14):

(...) não é preciso perguntar-se se nós percebemos verdadeiramente um mundo, é preciso dizer, ao contrário: o mundo é aquilo que nós percebemos. (...) O mundo não é não aquilo que eu penso, mas aquilo que eu vivo; eu estou aberto ao mundo, comunico indubitavelmente com ele, mas não o possuo, ele é inesgotável.

Justamente por ser fugidio, o termo é paradigmático do quanto é relevante ater-se à sintaxe enquanto tecido conectivo dos juízes: todo significado é definido por relação. Um chapéu sobre a cabeça de um camponês é um simples utilitário de proteção contra o sol; sobre a cabeça de uma dama de cerimônia, é um adorno; na fronte de um cardeal, é um símbolo de poder; na mão estendida de um mendigo, significa um pedido de auxílio. Do mesmo modo, um cachimbo na poltrona do escritório indica circunspecção e tranquilidade; no volante de um veículo, extravagância; no interior de um quadro de hospital, desrespeito e insensibilidade. (Fiorin \& Platão, 1998). Ou seja, no mundo da vida, do mesmo modo como no mundo mágico da ficção, o contexto - dimensão de espaço e de tempo - interfere no significado das ações dos personagens. Deste modo, sem o princípio metódico da evidência no próprio mundo da vida, "a linguagem comum é fugidia, equívoca, muito pouco exigente quanto à adequação dos termos”. É justamente por isso que, nas situações onde seus meios de expressão são empregados "será preciso conferir às significações um novo fundamento, orientá-los de modo original sobre esses significados fundamentados em nova forma” (Husserl, 1931/2001, p. 31): a descrição da estrutura total da experiência vivida e seus respectivos significados para os seres que a vivenciam.

Se cada item de um verbete de um dicionário comum, ao remeter às diversas significações possíveis para o termo sentido, nos falam de rosas individuais, neste ensaio o que buscamos alcançar foi o buquê. A fenomenologia nos ajudou neste processo justamente por contrapor-se a um determinado modo de fazer ciência psicológica que privilegia os métodos meramente analíticos, de decomposição da realidade em partes, como se as partes fossem mais importantes que o todo, ou como se apenas fosse possível compreender o todo a partir da soma das partes. Ora, quando enviamos ou recebemos um buquê, se o exame de cada rosa reduz-se à percepção da mesma como pedúnculo, receptáculo, sépalas, estames, carpelos, antera, gineceu, etc, tal como faria o biólogo ao fragmentar a flor em infinitas partes, o sentido do buquê, como um todo, desaparece. Cadê a poesia que estava alí? Ora, no mundo da vida, as rosas são vividas como beleza, como romance, como amor, enfim, como significação. Podemos fatiar a rosa inteira, mas nunca vamos encontrar toda a beleza dela nas suas partes. E mesmo que as rosas não falem, sua poesia só é apreendida no todo, como bem sabem os poetas.

Com isso, no entanto, não estamos afirmando que o método analítico não sirva para nada e que deva, simplesmente, ser substituído. Propomos apenas a superação do equívoco de acreditarmos na soberania de sua perspectiva. Estamos, portanto, chamando a atenção para a importância de se olhar também para o todo, pois é assim que a realidade se apresenta em nossas vidas. A fragmentação da realidade obstrui a apreensão da multiplicidade na unidade e respectiva amplidão do sentido das coisas, posto que este só pode ser apreendido num movimento de síntese, integrativo.

Se olharmos para o verbete-buquê - os sentidos do sentido - apenas de modo analítico, estamos nos alienando do mundo da vida, justamente o jardim provedor de todas as flores que o constituem. E ao fazemos isso, estamos condenando toda uma civilização ao padecimento das duras consequências de uma perspectiva meramente tecnicista, alienada do próprio solo que a fertiliza. É verdade que, ao nos voltarmos para o jardim - o sentido dos sentidos, certamente que não encontramos aí apenas as flores. Nele há ainda, dentre outras tantas coisas, os instrumentos do jardineiro, assim como também o estrume que fertiliza o solo. Devemos reconhecer, no entanto, tal como nos recomenda o poético Wittgenstein (1980/1996) nos seus manuscritos, o que aí os distingue não é meramente o seu valor, mas - sobretudo - suas funções no jardim. Acreditamos que distinguir e reconhecer tais funções se torna absolutamente imprescindível tanto para a ciência quanto para a prática psicológica que se queiram realmente efetivas no mundo da vida.

\section{Referências}

Amatuzzi, M. M. (1996). O uso da versão de sentido na formação e pesquisa em Psicologia. In R. M. L. L. Carvalho (org.), Repensando a formação do psicólogo: da informação à descoberta (pp. 12-24). Coletâneas da ANPEPP, 1 (9).

Barthes, R. (2008). Introdução a Análise Estrutural da Narrativa. In R. Barthes e cols. Análise Estrutural da Narrativa (pp. 18-58). (M. Pinto, Trad.). Petrópolis: Vozes. (Publicação original em 1966).

Bicudo, M.A.V. \& Cappelletti, I. F. (org.) (1999). Fenomenologia: uma visão abrangente da educação. São Paulo: Olho d’Água.

Castro, R. C.; Castro, M. C. \& Castro, J. C. (2009). A comunicação linguística de uma perspectiva da Fenomenologia de E. Husserl. Contingentia, 4(1): 93-107.

Chauí, M. (2003). Convite à filosofia. São Paulo: Ática.

Collins Thesaurus (2003-2008). Meaning. Princeton University, USA. [Citado 02 outubro 2010]. Disponível na World Wide Web: http://www.thefreedictionary.com/meaning 
Dartigues, A. (1973). O que é fenomenologia? (M. J. J. G. de Almeida, Trad.). Rio de Janeiro: Eldorado.

Dicionário Priberam da Língua Portuguesa (2010). Sentido. [Citado 22 abril 2010] Disponível na World Wide Web: http:// www.priberam.pt/dlpo/dlpo.aspx?pal=Sentido

Durozol, G. \& Roussel, A. (1996). Dicionário de Filosofia. (M. Appenzeller, Trad.) Campinas: Papirus.

Fiorin, J. L. \& Platão, S. (1998). Lições de texto: leitura e redação (3a. Ed.). São Paulo: Ática.

Gilbert, D. T. (2006). O que nos faz felizes: o futuro nunca é o que imaginamos. (L. Marinho, Trad.). Rio de Janeiro: Elsevier.

Houaiss, A. \& Villar, M. S. (2001). Dicionário Eletrônico Houaiss [Versão eletrônica]. Rio de Janeiro: Objetiva.

Husserl, E. (2000). A sexta investigação. São Paulo: Nova Cultural. (Original de 1901)

Husserl, E. (2001). Meditações Cartesianas: Introdução à fenomenologia. São Paulo: Madras. (Publicação original em 1931).

Husserl, E. (2008). A crise da humanidade europeia e a filosofia. (U. Zilles, Int. e trad.; $3^{\mathrm{a}}$ Ed.). Porto Alegre: EDIPUCRS. (Original de 1935)

Japiassu, H. \& Marcondes, D. (1996). Dicionário básico de filosofia. (3. Ed.). Rio de Janeiro: Zahar.

Martins, J. \& Bicudo, M. A. V. (1989). A pesquisa qualitativa em psicologia: Fundamentos e recursos básicos. São Paulo: EDUC.

Merleau-Ponty, M. (1973). Ciências do Homem e Fenomenologia. (S. T. Muchail, Trad.). São Paulo: Saraiva. (Original de 1951).

Merleau-Ponty, M. (1999). Fenomenologia da percepção. São Paulo: Martins Fontes. (Original de 1945).

Michaelis (1998/2009) - Moderno Dicionário da Língua Portuguesa. [Citado 22 abril 2012]. São Paulo: Melhoramentos. Disponível na World Wide Web: http://michelis.uol. com.br/moderno/portugues/index.php?lingua=portugues -portugues\&palavra=sentido.
Silva, M. L. (2009). A intencionalidade da consciência em Husserl. Argumentos: Revista de Filosofia, 1(1): 45-53.

Sousa. L. G. (2006). Ética e sociedade. Espanha, Málaga: Eumed. Net.

Sokolowski, R. (2010). Introdução à fenomenologia. (A. O. Moraes, Trad.). São Paulo: Loyola.

Zilles, U. (2001). Os conceitos husserlianos de "lebenswelt" e teleologia. In R. T. Souza, \& N. F. Oliveira (Org.). Fenomenologia hoje: existência, ser e sentido no limiar do século XXI (pp. 509-519). Porto Alegre: EDIPUCRS.

Zilles, U. (2002). Fenomenologia Husserliana como Método Radical. Em E. Husserl. A crise da humanidade européia e a filosofia [pp. 08-41]. Porto Alegre: EDIPUCRS.

Marta Helena de Freitas - Doutora em Psicologia pela Universidade de Brasília (UnB), com Pós-Doutorado na University of Kent at Canterbury (Inglaterra). Atualmente é Professora e Pesquisadora do Programa de Pós-Graduação Stricto Sensu em Psicologia da Universidade Católica de Brasília (UCB). Endereço Institucional: Universidade Católica de Brasília, Pró-Reitoria de Pós-Graduação e Pesquisa, Mestrado em Psicologia. SGAN 916, Módulo B, W5 Norte (Asa Norte). CEP 70790-160, Brasília, DF.Email: mhelena@ucb.br

Rita de Cássia Araújo - Mestre em Psicologia pela Universidade Católica de Brasília (UCB) e Psicoterapeuta na CLIMAI (Brasília). Email: ritaholsback@yahoo.com.br

Filipe Starling Loureiro Franca - Mestre em Psicologia pela Universidade Católica de Brasília (UCB) e Psicoterapeuta em Brasília. Email: filipe.starling@gmail.com

Ondina Pena Pereira - Doutora em Filosofia pela Universidade de Brasília (UnB), Professora e Pesquisadora do Programa de Pós-Graduação Stricto Sensu em Psicologia da Universidade Católica de Brasília (UCB). Email: ondina@pos.ucb.br

Francisco Martins - Doutor em Psicologia pela Universidade de Louvain (Bélgica), Professor Titular da Universidade de Brasília, Psiquiatra, Psicanalista, Professor e Pesquisador do Programa de Pós-Graduação Stricto Sensu em Psicologia da Universidade Católica de Brasília (UCB).Email: fmartins@unb.br

Recebido em 25.04.2012 Aceito em 26.09.2012 